\title{
Rivaroxaban and other novel oral anticoagulants: pharmacokinetics in healthy subjects, specific patient populations and relevance of coagulation monitoring
}

\author{
Wolfgang Mueck*, Stephan Schwers and Jan Stampfuss
}

\begin{abstract}
Unlike traditional anticoagulants, the more recently developed agents rivaroxaban, dabigatran and apixaban target specific factors in the coagulation cascade to attenuate thrombosis. Rivaroxaban and apixaban directly inhibit Factor $\mathrm{Xa}$, whereas dabigatran directly inhibits thrombin. All three drugs exhibit predictable pharmacokinetic and pharmacodynamic characteristics that allow for fixed oral doses in a variety of settings. The population pharmacokinetics of rivaroxaban, and also dabigatran, have been evaluated in a series of models using patient data from phase II and III clinical studies. These models point towards a consistent pharmacokinetic and pharmacodynamic profile, even when extreme demographic factors are taken into account, meaning that doses rarely need to be adjusted. The exception is in certain patients with renal impairment, for whom pharmacokinetic modelling provided the rationale for reduced doses as part of some regimens. Although not routinely required, the ability to measure plasma concentrations of these agents could be advantageous in emergency situations, such as overdose. Specific pharmacokinetic and pharmacodynamic characteristics must be taken into account when selecting an appropriate assay for monitoring. The anti-Factor Xa chromogenic assays now available are likely to provide the most appropriate means of determining plasma concentrations of rivaroxaban and apixaban, and specific assays for dabigatran are in development.
\end{abstract}

Keywords: Rivaroxaban, Population Pharmacokinetics, Dabigatran, Apixaban, Coagulation Monitoring

\section{Introduction}

In recent years, the scope for effective management of venous and arterial thromboembolic diseases has been enhanced by the advent of novel oral anticoagulants (OACs) that, unlike traditional oral vitamin $\mathrm{K}$ antagonists (VKAs) [1], are given at fixed doses and have a lower potential for drug and food interactions [2]. These agents show similar or improved efficacy and safety profiles compared with VKAs, such as warfarin, and established parenteral agents, including unfractionated heparin and low molecular weight heparin [2].

The currently licensed novel OACs are rivaroxaban (Xarelto ${ }^{\circledR}$, Bayer Pharma AG and Janssen Pharmaceuticals, Inc.), dabigatran (Pradaxa ${ }^{\circledR}$, Boehringer Ingelheim

\footnotetext{
* Correspondence: wolfgang.mueck@bayer.com

Bayer Pharma AG, Clinical Pharmacology, D-42096 Wuppertal, Germany
}

International $\mathrm{GmbH}$ ) and apixaban (Eliquis ${ }^{\circledR}$, BristolMyers Squibb and Pfizer EEIG). All three of these agents, and others in development, are under investigation for the management of multiple thromboembolic disorders. Rivaroxaban, a direct Factor Xa inhibitor, is now approved in the European Union (EU), United States (US) and elsewhere for the prevention of venous thromboembolism (VTE) in adults who have undergone elective hip or knee replacement surgery at a dose of $10 \mathrm{mg}$ once daily (od) given for 2 weeks (knee) or 5 weeks (hip) [3,4]. Apixaban [5], another direct Factor Xa inhibitor, and dabigatran [6], a direct thrombin inhibitor, are now also approved in the EU for the same orthopaedic indication. In addition, rivaroxaban is approved for the prevention of stroke and systemic embolism in adults with non-valvular atrial fibrillation (AF) (20 mg od; EU and US) [3,4], and for the treatment of
() Biomed Central 
deep vein thrombosis (DVT) and pulmonary embolism (PE), and prevention of recurrent DVT and PE in adult patients (15 mg twice daily [bid] for 3 weeks followed by $20 \mathrm{mg}$ od; EU and US) [3,4]. Apixaban and dabigatran are also licensed to reduce the risk of stroke and systemic embolism in patients with non-valvular AF in Europe and the US [5-8]. Rivaroxaban has also recently been approved in the EU for the secondary prevention of acute coronary syndrome (ACS); rivaroxaban administered with acetylsalicylic acid (ASA) alone or with ASA plus clopidogrel or ticlopidine is indicated for the prevention of atherothrombotic events in adult patients with elevated cardiac biomarkers after ACS [3].

The novel OACs have mechanisms of action that attenuate thrombotic processes via direct targeting of specific factors in the coagulation cascade [9]. An essential component of the clinical development of these agents has been a full characterisation of their pharmacokinetic (PK) and pharmacodynamic (PD) profiles. In particular, the phase III clinical trial programme for rivaroxaban has been supported by a comprehensive set of phase I and II studies evaluating PK and PD in both healthy subjects and patients receiving the drug for active prevention or treatment of thrombosis [10-12]. These studies have demonstrated the predictable $\mathrm{PK}$ and $\mathrm{PD}$ properties of rivaroxaban that allow fixed oral dosing regimens to be followed, as well as characterising other important aspects, such as limited clinically relevant drug-drug interactions [10].

Because of their predictable PK/PD profiles, rivaroxaban and other novel OACs do not require routine coagulation monitoring [2]. However, there are circumstances in which it may be necessary or desirable to measure their anticoagulant effect or the plasma levels of these drugs [9]. In such cases, it is important to appreciate the PK properties of the drugs and their influence on coagulation assays. The objectives of this review are to provide an overview of the mechanism of action of rivaroxaban, to summarise its known PK and PD characteristics in healthy subjects and patient populations, and to give information on potential laboratory tests for rivaroxaban. Dabigatran and apixaban are discussed where relevant differences exist.

\section{Mechanism of action of novel oral anticoagulants}

Unlike traditional anticoagulant agents, the VKAs and heparins, novel OACs have been designed to inhibit specific single targets in the coagulation cascade (Figure 1) [9]. Rivaroxaban and apixaban directly inhibit Factor Xa, whereas dabigatran targets thrombin (Factor IIa). In addition, the parenteral agent fondaparinux indirectly inhibits Factor Xa (Figure 1).

Rivaroxaban, the first oral, direct Factor Xa inhibitor to be developed, was designed to specifically target Factor Xa for several reasons. Factor Xa occupies the crossroads

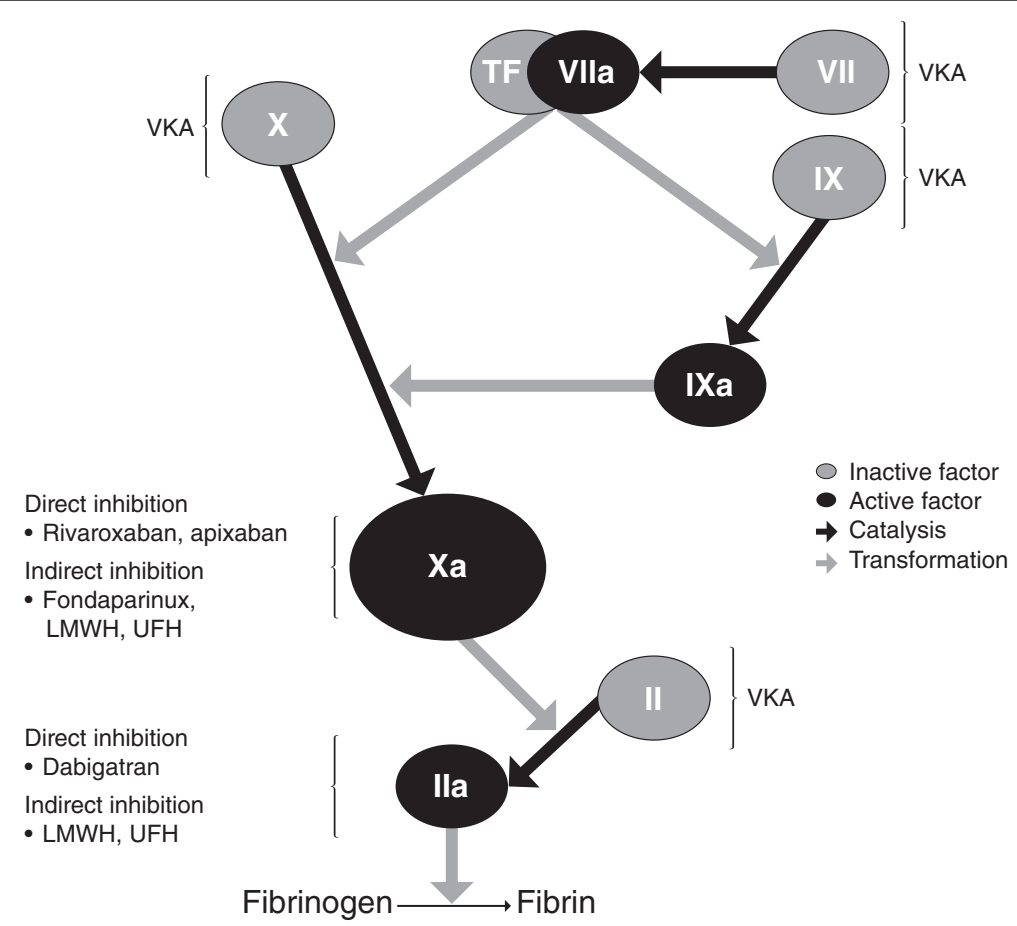

Figure 1 The coagulation cascade and targets of anticoagulant agents. LMWH, low molecular weight heparin; TF, tissue factor; UFH, unfractionated heparin; VKA, vitamin $\mathrm{K}$ antagonist [9]. 
between the intrinsic and extrinsic pathways in the coagulation process [13] and is responsible for converting prothrombin (Factor II) to thrombin (Factor IIa) [14]. In preclinical studies, rivaroxaban was found to be highly selective for Factor Xa, with an inhibitory effect $>10,000$ fold higher than for related serine proteases and an inhibition constant $\left(\mathrm{K}_{\mathrm{i}}\right)$ of $0.4 \mathrm{nmol} / \mathrm{l}$ [10]. Importantly, rivaroxaban was shown to inhibit free, prothrombinase-associated and clot-associated Factor Xa without having a direct effect on platelet aggregation [15]. This is in contrast to the indirect Factor Xa inhibitors, such as fondaparinux, which do not inhibit Factor Xa that is bound to the prothrombinase complex [16]. Unlike rivaroxaban, fondaparinux also requires an antithrombin cofactor [9]. Because rivaroxaban does not inhibit thrombin directly, rivaroxaban does not affect the haemostatic function of pre-existing thrombin molecules [16].

Given the central role of thrombin in coagulation, direct targeting of this factor results in an antithrombotic effect. Thrombin is produced in small amounts in the initiation phase of the coagulation cascade but is generated in much greater amounts in the propagation phase and is essential to the amplification of coagulation and the formation of fibrin [14].

\section{Pharmacokinetic and pharmacodynamic properties of rivaroxaban and other novel oral anticoagulants in healthy volunteers and specific patient populations}

Phase I studies in healthy volunteers and special populations

In phase I studies in healthy subjects, rivaroxaban was found to have predictable PK properties (Table 1), with high absolute bioavailability after oral dosing [10,17], high and reversible plasma protein binding and a mean terminal half-life of 5-13 hours after a $10 \mathrm{mg}$ dose $[3,18]$. Systemic clearance was low (approximately $10 \mathrm{l} / \mathrm{h}$ ) [3]. Unchanged rivaroxaban was the predominant compound found in human plasma, and no major or active circulating metabolites were detected [19]. After single doses of 1.25-80 mg, which were well tolerated and did not lead to an increased risk of bleeding, peak plasma concentrations occurred within 2-4 hours of dosing, and maximal Factor Xa inhibition was seen after 1-4 hours [17]. This fast onset of action is similar to that of the low molecular weight heparins; for enoxaparin, maximum plasma anti-Factor Xa activity occurs 1-4 hours after injection [20]. The half-life of the biological effect of rivaroxaban was 6-7 hours, with Factor Xa inhibition still evident 24 hours after the administration of doses $>5 \mathrm{mg}$ [17]. Rivaroxaban was selective for Factor $\mathrm{Xa}$ inhibition and had no direct effect on thrombin and no effect on antithrombin activity [17]. When multiple doses up to $30 \mathrm{mg}$ bid were given for 7 days, Factor Xa activity was inhibited in a dose-dependent manner, reaching a maximum after approximately 3 hours and continuing for at least 12 hours [21]. Peak plasma concentrations were reached after 3-4 hours and the terminal half-life was 5.79.2 hours at steady state, without accumulation at any dose [21]. The systemic clearance and volume of distribution in healthy volunteers are approximately $10 \mathrm{l} / \mathrm{h}$ and 50 litres, respectively, with moderate interindividual variability [3] For single and multiple doses, prolongation of coagulation tests followed a similar profile to Factor Xa inhibition and correlated closely with plasma concentrations [22].

Several phase I studies were also conducted in special patient populations. These indicated that relevant PK and PD parameters remained consistent regardless of body weight [26], age $[27,28]$, gender $[28,29]$ or ethnicity $[29,30]$, suggesting that dose adjustment is unnecessary. However, the presence of hepatic and renal impairment may lead to relevant PK/PD effects. For a $10 \mathrm{mg}$ dose, mild hepatic impairment (Child-Pugh A) led to minimal PK and no PD changes compared with healthy controls, although moderate impairment (Child-Pugh B) led to significant increases in exposure and associated enhanced Factor Xa inhibition [3,31]; there are no data in patients with severe hepatic impairment. Approximately two-thirds of a rivaroxaban dose undergoes metabolic degradation, of which half is eliminated renally and half via the hepatobiliary route; the other one-third of the administered dose is excreted directly via the kidneys as unchanged, active drug, principally through active renal

Table 1 Pharmacokinetic parameters (median values) of rivaroxaban, apixaban and dabigatran in healthy adults

\begin{tabular}{|c|c|c|c|c|c|c|c|c|c|}
\hline Agent & $\mathrm{F}_{\mathrm{abs},} \%$ & $C_{\max }, \mathrm{ng} / \mathrm{ml}$ & AUC, $\mathrm{ng} \cdot \mathrm{h} / \mathrm{ml}$ & $t_{\max }, h$ & $t_{1 / 2}, h$ & $V_{d}, I$ & $\mathrm{CL} / \mathrm{F}, \mathrm{I} / \mathrm{h}$ & $\begin{array}{c}\text { Plasma protein } \\
\text { binding, } \%\end{array}$ & $\begin{array}{c}\text { Renal excretion } \\
\text { of unchanged } \\
\text { drug, } \%\end{array}$ \\
\hline Rivaroxaban & 80-100 [3] & $141^{*}[17]$ & $1020^{*}[17]$ & $2-4[3]$ & $5-13[3]$ & $50[3]$ & 10 [3] & $92-95$ [3] & $33[3]$ \\
\hline Apixaban & $50[5]$ & $460^{\dagger}[23]$ & $4100^{\dagger}[23]$ & $3-4[5]$ & $12[5]$ & $21[5]$ & $3[5]$ & $87[5]$ & $27[5]$ \\
\hline Dabigatran & $6.5[6]$ & $110^{\ddagger}[24]$ & $900^{\ddagger}[24]$ & $1-2[6]$ & $12-17[6]$ & $60-70[6]$ & $105-170[24]$ & $34-35[6]$ & $85[25]$ \\
\hline
\end{tabular}

*With $10 \mathrm{mg}$ oral dose.

${ }^{+}$With $20 \mathrm{mg}$ oral dose.

"With $150 \mathrm{mg}$ oral dose.

Values rounded to nearest integer.

AUC area under the concentration-time curve, $C L / F$ apparent clearance, $C_{\max }$ maximum plasma concentration, $F_{a b s}$ absolute bioavailability, $t_{\max }$ time to maximum concentration, $t_{\frac{1}{2}}$ apparent half-life, $v_{d}$ volume of distribution at steady state. 
secretion via the transporter proteins P-glycoprotein (P-gp) and breast cancer resistance protein $[3,19]$. This gives an overall renal clearance of $3-4 \mathrm{l} / \mathrm{h}$, meaning that decreasing renal function leads to an increase in rivaroxaban plasma concentrations and, correspondingly, PD effects [32]. No data exist for patients with creatinine clearance $(\mathrm{CrCl}) \mathrm{min} / \mathrm{min}$. As a result of high plasma protein binding $(92-95 \%$ [3,18]), rivaroxaban is not expected to be dialysable [3].

Taking rivaroxaban with food did not have a significant effect on PK parameters for a $10 \mathrm{mg}$ dose compared with fasting [3], but decreases in maximum plasma concentration $\left(\mathrm{C}_{\max }\right)$ and overall exposure (area under the concentration-time curve, AUC) were evident at a dose of $20 \mathrm{mg}$ in the fasted state [33], as a result of decreased bioavailability and absorption rate with increasing dose [22]. When a dose of $20 \mathrm{mg}$ was administered with food, complete bioavailability of rivaroxaban was restored [34]. Absorption was not affected by changes in gastric $\mathrm{pH}$ induced by ranitidine or antacid [33]. Because rivaroxaban is metabolised via cytochrome P450 (CYP) 3A4, CYP2J2 and CYP-independent mechanisms, and active renal secretion is mediated by $\mathrm{P}$-gp and breast cancer resistance protein, co-administration with strong inhibitors of both CYP3A4 and P-gp, such as the azole antimycotic ketoconazole or the HIV protease inhibitor ritonavir, led to increased exposure and PD effects [3,35]. Strong inhibitors of one or the other, or moderate inhibitors of both of these pathways produced less marked effects [3,35]. Concomitant administration of rivaroxaban and strong CYP3A4 and P-gp inducers, such as the antibiotic rifampicin, led to decreases in PK and PD effects, whereas interactions with substrates of CYP3A4 and/or P-gp were considered not to be clinically relevant. Rivaroxaban does not inhibit or induce any major CYP isoforms, such as CYP3A4 [3]. Co-administration with enoxaparin produced an additive PD effect but did not affect the PK of rivaroxaban [3,36]. Clopidogrel did not affect rivaroxaban PK but did lead to a relevant increase in bleeding time in approximately one-third of healthy subjects, although this was not correlated with changes in platelet aggregation [37]. Co-medication with naproxen or ASA did not lead to clinically relevant prolongation of bleeding time overall [38], but some individuals exhibited pronounced PD effects with rivaroxaban plus ASA [39].

Apixaban and dabigatran exhibit broadly similar PK profiles to rivaroxaban, but with some notable exceptions (Table 1). Unlike apixaban and rivaroxaban, dabigatran is administered as a prodrug (dabigatran etexilate). The latter is a substrate of P-gp and its low oral bioavailability is determined by intestinal P-gp transporters [40]. Once absorbed, the prodrug is rapidly converted to dabigatran by esterases [40]. The volume of distribution of apixaban [5] is lower than that of rivaroxaban [3] and dabigatran [6], which in turn exhibit higher clearance and lower protein binding. An important difference between the drugs is also the proportion of each that is excreted via the kidneys; renal elimination of apixaban (approximately 27\%; the majority is excreted via the hepatobiliary route) [5] is slightly lower than that of rivaroxaban [3], but that of dabigatran is considerably higher (85\%) [25]. Unlike rivaroxaban [3] and apixaban [5], neither dabigatran nor its prodrug are metabolised by CYP-dependent mechanisms [6]; however, owing to dabigatran etexilate being a P-gp substrate, the effect of P-gp inhibitors on the bioavailability of dabigatran is stronger than on rivaroxaban elimination [6].

\section{Venous thromboembolism prevention in the orthopaedic setting}

All three approved novel OACs underwent initial clinical evaluation for the prevention of VTE after elective hip or knee replacement surgery. This population experiences high levels of post-operative VTE in the absence of adequate thromboprophylaxis [41]. The rivaroxaban phase III clinical programme comprised four studies, RECORD1 [42], RECORD2 [43], RECORD3 [44] and RECORD4 [45], in more than 12,500 patients undergoing elective total hip replacement (THR) or total knee replacement (TKR). All four trials showed a significant efficacy benefit with rivaroxaban over the comparator enoxaparin regimens without an increase in major bleeding, and this was confirmed by pooled analyses $[46,47]$. The preceding phase II clinical trials (ODIXa-HIP [48], ODIXa-HIP2 [49], ODIXa-KNEE [50] and ODIXaHIP-OD [51]) of rivaroxaban for VTE prevention in patients undergoing THR or TKR collected data that were used to construct population PK/PD models to characterise the PK and PD properties of rivaroxaban in orthopaedic surgery populations $[11,52]$. One model compared rivaroxaban od and bid doses in patients undergoing THR and investigated the influence of patient demographic characteristics on PK and PD parameters [11]. Only doses that had demonstrated a favourable profile compared with enoxaparin, i.e. total daily doses of 5-20 mg, were considered. The other model included both THR and TKR patients from the phase II programme [52]. In both models, PK data were fed into a non-linear mixed effects model (NONMEM), which allows population estimates to be derived for PK and PK/ PD parameters and quantifies both the interindividual and interoccasion variability of these parameters, as well as residual (unexplained) variability. Importantly, inputs to the model could then be modified to simulate the effect of different dosing regimens and population demographic factors (such as age, renal function and body weight) and the effect of co-medications [11,52].

In the first model described above, a total of 5743 samples from 758 patients ( 362 patients from the bid study and 396 patients from the od study) were included. Patient demographics were similar between the rivaroxaban od and 
bid study populations [11]. Observed rivaroxaban plasma concentrations (mean, 5/95 percentiles) are shown in Table 2. An oral, one-compartment model with a firstorder rate constant was found to accurately describe the $\mathrm{PK}$ of rivaroxaban. The results of the model confirmed that rivaroxaban exhibited a predictable, dose-proportional PK profile in THR patients, as it had in healthy volunteers, with similar values for PK parameters (Table 3). The maximum plasma concentration $\left(C_{\max }\right)$ for a $10 \mathrm{mg}$ od dose was similar to that in healthy volunteers (median $125 \mathrm{ng} / \mathrm{ml}$ vs $141 \mathrm{ng} / \mathrm{ml})$. Steady-state trough concentrations $\left(\mathrm{C}_{\text {trough }}\right)$ were a median of approximately $9 \mathrm{ng} / \mathrm{ml}$; this value was in the order of magnitude required for in vitro inhibition of Factor Xa activity, which supported the use of the rivaroxaban $10 \mathrm{mg}$ od dose [11]. PK parameters were affected by body weight, study day, age, renal function, serum albumin and haematocrit, but the average of these effects remained within the overall variability of the population. The residual variability of the model was moderate (52.6\%). PK/PD analysis of both the rivaroxaban od and bid data indicated that prolongation of prothrombin time (PT), measured using the STA ${ }^{\circledR}$ Neoplastine ${ }^{\circledR}$ CI Plus assay (Diagnostica Stago, Parsippany, NJ, USA), correlated strongly with rivaroxaban plasma concentrations [11].

In order to provide insight into the expected influence of patient demographics, the model was then used to simulate the PK of rivaroxaban $10 \mathrm{mg}$ od in patients with extreme characteristics; this included age 90 years, moderate to severe renal impairment (creatinine clearance $[\mathrm{CrCl}] 30 \mathrm{ml} /$ min), low body weight (40 kg) and combined age 90 years and low body weight. The predicted plasma concentration-time profiles of rivaroxaban for the typical individual in each of the four demographic groups fell within the predicted $90 \%$ confidence intervals for the average population in these studies (Figure 2), confirming that rivaroxaban $10 \mathrm{mg}$ od could be given without the need for dose adjustment in THR patients regardless of factors such as old age and moderate renal impairment [11]. In the second model, the only major difference between PK properties for TKR and THR was that clearance was $26 \%$ lower in the knee study, which led to $\sim 30 \%$ greater exposure. The models exhibited moderate residual variability (37\% and $34 \%$ in the hip and knee studies, respectively) [52].

In its phase III clinical programme, dabigatran $150 \mathrm{mg}$ and/or $220 \mathrm{mg}$ od were compared with enoxaparin regimens for the prevention of total VTE in patients who had undergone TKR (RE-MODEL [53] and RE-MOBILIZE [54] trials) or THR (RE-NOVATE [55] and RENOVATE II [56] studies). As with rivaroxaban, the doses used in these phase III trials were determined by a series of phase II studies, and one of these (BISTRO I) also provided PK data that could be used to construct a population PK model [57]. In total, 289 patients received dabigatran at doses of 150 or $300 \mathrm{mg}$ od or 12.5-300 mg bid, and 4604 blood samples were available for use in the model [57]. Unlike for rivaroxaban, a two-compartment model most accurately described the PK profile of dabigatran, which demonstrated dose-proportionality and linear kinetics. The rate of drug absorption and apparent clearance during days 0 and 1 of treatment were significantly lower $(\mathrm{p}<0.001)$ than on days $2-10$, which may be explained by changes in gastrointestinal motility caused by surgical effects or co-medication; a similar finding was reported in the rivaroxaban models for this patient population. Weight, gender, variations in most laboratory measurements, smoking and alcohol consumption did not affect the PK of dabigatran but, unsurprisingly for a drug with $80 \%$ renal clearance, decreasing $\mathrm{CrCl}$ significantly increased plasma exposure [57]. Despite this, simulations indicated an apparent degree of overlap in concentration-time profiles for renally impaired patients compared with unimpaired controls, supporting the use of fixed dabigatran doses in patients undergoing THR regardless of demographic factors [57].

The phase III programme investigating apixaban for VTE prophylaxis after THR or TKR surgery consisted of three studies, ADVANCE-1, ADVANCE-2 and ADVANCE-3 [58-60], which compared apixaban $2.5 \mathrm{mg}$ bid with standard enoxaparin regimens. No population PK model for apixaban in the orthopaedic setting has yet been published.

\section{Treatment of acute deep vein thrombosis and prevention} of recurrent venous thromboembolism

VTE is a major global healthcare problem that carries a substantial morbidity and mortality burden in the general population $[61,62]$. The phase III EINSTEIN DVT [63] and EINSTEIN PE [64] studies assessed a singledrug approach using rivaroxaban against the standard dual-drug approach of enoxaparin overlapping with a VKA in patients with confirmed acute symptomatic DVT or PE. These studies found that rivaroxaban was as effective as this standard regimen with similar or better safety outcomes. An extension study (EINSTEIN EXT) indicated that long-term rivaroxaban was also more effective than placebo in preventing recurrent VTE [63]. Given that high rates of VTE recurrence in the acute phase of treatment were seen in previous studies $[65,66]$, a higher dose of rivaroxaban (15 mg bid) was employed in the first 3 weeks of treatment. The basis for the chosen regimen $(15 \mathrm{mg}$ bid for 3 weeks followed by $20 \mathrm{mg}$ od) stemmed from the outcomes from two phase II studies (EINSTEIN and ODIXa-DVT) [67,68], which demonstrated a greater reduction in thrombosis burden with bid compared with od dosing in the acute phase of treatment. These studies also collected PK data to produce a population model to characterise the PK/PD of rivaroxaban od and bid doses in patients with acute DVT, including evaluation of the influence of demographic factors. 
Table 2 Concentration-time profiles for rivaroxaban in different patient populations observed in clinical studies [Bayer HealthCare Pharmaceuticals and Janssen Research \& Development, LLC; data on file]

\begin{tabular}{|c|c|c|c|c|c|}
\hline \multirow{2}{*}{$\begin{array}{l}\text { Indication and } \\
\text { rivaroxaban } \\
\text { dose }\end{array}$} & VTE prevention: & DVT treatment: & $\begin{array}{l}\text { Prevention of stroke in patients with } \mathrm{AF} \\
\text { and } \mathrm{CrCl} \geq 50 \mathrm{ml} / \mathrm{min} \text { : }\end{array}$ & $\begin{array}{l}\text { Prevention of stroke in patients with } \mathrm{AF} \\
\text { and } \mathrm{CrCl}<50 \mathrm{ml} / \mathrm{min} \text { : }\end{array}$ & $\begin{array}{l}\text { Prevention of CV events in } \\
\text { patients with ACS: }\end{array}$ \\
\hline & $10 \mathrm{mg}$ od & $\begin{array}{l}15 \mathrm{mg} \text { bid for } 3 \text { weeks } \\
\text { followed by } 20 \mathrm{mg} \text { od }\end{array}$ & $20 \mathrm{mg}$ od & $15 \mathrm{mg}$ od & $2.5 \mathrm{mg}$ bid \\
\hline $\begin{array}{l}\text { Time after } \\
\text { dosing (hours) }\end{array}$ & $\begin{array}{c}\text { Concentration, } \mu \mathrm{g} / \mathrm{l} \\
(5 / 95 \text { percentile })\end{array}$ & $\begin{array}{c}\text { Concentration, } \mu \mathrm{g} / \mathrm{l} \\
(5 / 95 \text { percentile })\end{array}$ & $\begin{array}{c}\text { Concentration, } \mu \mathrm{g} / \mathrm{l} \\
(5 / 95 \text { percentile) }\end{array}$ & $\begin{array}{c}\text { Concentration, } \mu \mathrm{g} / \mathrm{l} \\
(5 / 95 \text { percentile })\end{array}$ & $\begin{array}{c}\text { Concentration, } \mu \mathrm{g} / \mathrm{l} \\
(5 / 95 \text { percentile })\end{array}$ \\
\hline 1 & $111(75.1-177)$ & $235(164-361)$ & $216(152-316)$ & $189(134-281)$ & $41.3(23.5-65.9)$ \\
\hline 2 & $122(90.6-195)$ & 270 (189-419) & $250(177-361)$ & $219(157-317)$ & $44.1(26.7-69.5)$ \\
\hline 3 & $114(82.3-186)$ & 259 (180-405) & $246(172-361)$ & $216(153-317)$ & $42.0(25.9-66.4)$ \\
\hline 4 & $102(75.8-164)$ & $237(161-369)$ & 232 (157-349) & 205 (141-309) & $38.7(23.3-63.3)$ \\
\hline 5 & $90.7(62.2-143)$ & $213(145-339)$ & $215(140-333)$ & 191 (127-297) & $35.2(20.2-59.1)$ \\
\hline 6 & $80.2(51.8-125)$ & $191(123-311)$ & $198(123-318)$ & $177(111-286)$ & $31.7(17.4-55.5)$ \\
\hline 9 & $55.2(30.5-96.0)$ & 137 (71.3-240) & 155 (81.9-276) & 141 (74.9-254) & $22.8(10.4-45.2)$ \\
\hline 12 & $37.8(15.2-76.1)$ & $97.8(42.9-190)$ & $121(53.4-242)$ & $112(50.0-225)$ & $16.2(6.11-36.6)$ \\
\hline 18 & $17.9(4.85-49.9)$ & $50.0(16.0-124)$ & 73.5 (22.0-187) & 70.4 (21.9-180) & - \\
\hline 24 & $8.54(1.36-37.2)$ & $25.6(5.93-86.9)$ & $44.7(9.02-147)$ & $44.4(9.42-143)$ & - \\
\hline
\end{tabular}

Plasma concentrations given as geometric mean values with $90 \%$ prediction intervals (5/95 percentiles). Values given to 3 significant figures.

ACS acute coronary syndrome, AF atrial fibrillation, bid twice daily, $\mathrm{CrCl}$ creatinine clearance, $C V$ cardiovascular, DVT deep vein thrombosis, od once daily, VTE venous thromboembolism. 
Table 3 Comparison of selected pharmacokinetic parameters (median values) with rivaroxaban in specific patient populations

\begin{tabular}{|c|c|c|c|c|c|c|c|}
\hline Population and rivaroxaban dose & $\mathrm{C}_{\max ,} \mathrm{ng} / \mathrm{ml}$ & $\begin{array}{l}\text { C } C_{\text {troughr }} \\
\mathrm{ng} / \mathrm{ml}\end{array}$ & AUC, $\mathrm{ng} \cdot \mathrm{h} / \mathrm{ml}$ & $V_{d} / F, I$ & $\begin{array}{c}\text { Interindividual } \\
\text { variability in } \mathrm{V}_{\mathrm{d}} \% \mathrm{CV}\end{array}$ & $\mathrm{CL} / \mathrm{F}, \mathrm{l} / \mathrm{h}$ & $\begin{array}{c}\text { Interindividual } \\
\text { variability in } \mathrm{CL} / \mathrm{F}, \% \mathrm{CV}\end{array}$ \\
\hline Hip surgery patients, 2.5-10 mg bid; 10 mg od & $125^{*}[11]$ & $9^{*}[11]$ & $1170^{\dagger}[11]$ & 58 [11] & $32[11]$ & $5-8[11]$ & 38 [11] \\
\hline $\begin{array}{l}\text { Patients treated for DVT; } 10 \mathrm{mg} \text { bid, } 20 \text { and } \\
30 \mathrm{mg} \text { od or bid, or } 40 \mathrm{mg} \text { od }\end{array}$ & 270 [12] & $25^{\ddagger}[12]$ & $2870[12]$ & 54 [12] & 29 [12] & $6[12]$ & $40[12]$ \\
\hline Patients with AF; 15 and $20 \mathrm{mg}$ od & $\begin{array}{c}257^{\ddagger} \text { [Girgis. } \\
\text { Unpublished data] }\end{array}$ & 32 [12] & $\begin{array}{c}3466^{\dagger} \text { [Girgis. } \\
\text { Unpublished data] }\end{array}$ & $\begin{array}{l}80 \text { [Girgis. } \\
\text { Unpublished data] }\end{array}$ & $\begin{array}{l}18 \text { [Girgis. Unpublished } \\
\text { data] }\end{array}$ & $\begin{array}{c}6 \text { [Girgis. } \\
\text { Unpublished } \\
\text { data] }\end{array}$ & $\begin{array}{l}35 \text { [Girgis. Unpublished } \\
\text { data] }\end{array}$ \\
\hline Patients with ACS; $2.5 \mathrm{mg}$ bid & $44^{\S}[86]$ & $16^{\S}[86]$ & $361^{\S}[86]$ & $58[86]$ & $10[86]$ & $6.5[86]$ & $31[86]$ \\
\hline
\end{tabular}

*10 mg od.

${ }^{\dagger}$ AUC over a 24 -hour period at steady-state.

${ }^{\ddagger} 20 \mathrm{mg}$ od at steady-state.

${ }^{5} 2.5 \mathrm{mg}$ bid at steady-state; AUC over a 12-hour period.

Values rounded to nearest integer.

$A F$ atrial fibrillation, $A U C$ area under the concentration-time curve, bid twice daily, $C_{\max }$ maximum plasma concentration, $C_{\text {trough }}$ steady-state trough concentration, $C L / F$ apparent clearance, $C V$ coefficient of variance, DVT deep vein thrombosis, NR not reported, od once daily, $V_{d} / F$ volume of distribution at steady state. 


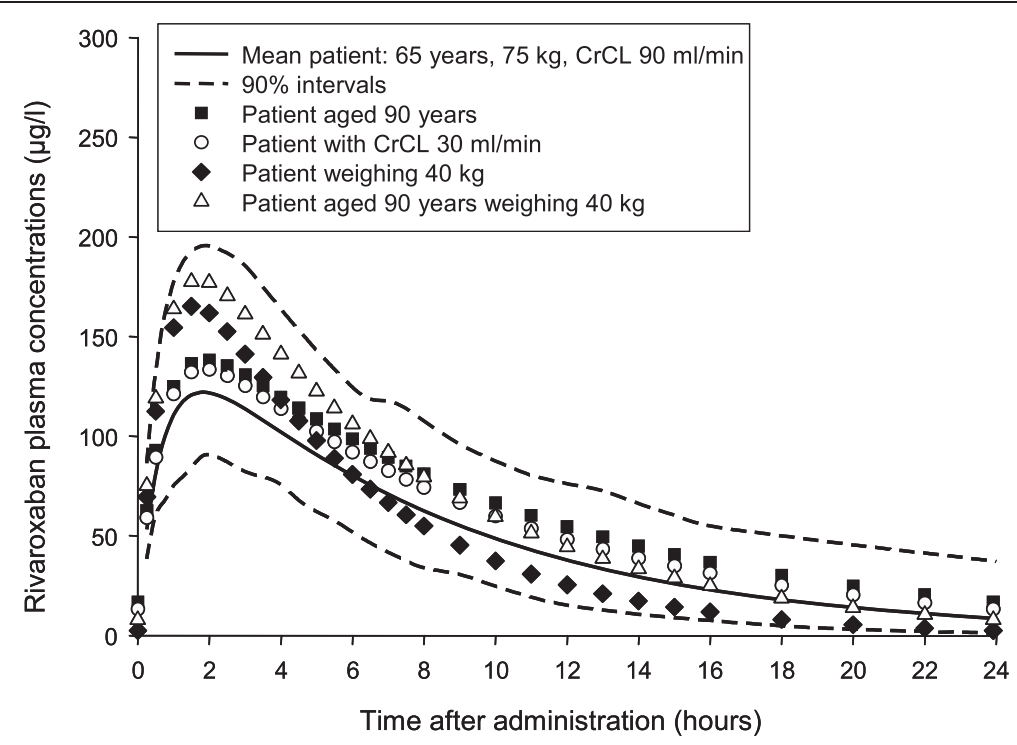

Figure 2 Simulations of rivaroxaban plasma concentration-time profiles in typical patients compared with overall population estimates. Typical patients are elderly (90 years), have moderate to severe renal impairment; $\mathrm{CrCl} 30 \mathrm{ml} / \mathrm{min}$ ), have low body weight (40 kg), or are elderly with low body weight. Patients receiving rivaroxaban $10 \mathrm{mg}$ once daily (mean with $90 \%$ interval) $[11]$. $\mathrm{CrCL} / \mathrm{CrCl}$, creatinine clearance. Reproduced with permission from Mueck W, Borris LC, Dahl OE et al. Population pharmacokinetics and pharmacodynamics of once- and twice-daily rivaroxaban for the prevention of venous thromboembolism in patients undergoing total hip replacement. Thromb Haemost 2008;100:453-461.

Data input into the model comprised 4634 rivaroxaban plasma samples from 870 patients [12]. Observed rivaroxaban plasma concentrations (mean, 5/95 percentiles) are shown in Table 2. As for healthy subjects and patients who had undergone major orthopaedic surgery, rivaroxaban PK was well described by a one-compartment model. Median $\mathrm{C}_{\max }, \mathrm{C}_{\text {trough }}$ and AUC values at steady state at the daily dose chosen for the phase III programme (20 mg od) were correspondingly higher than for a $10 \mathrm{mg}$ od dose (Table 3), and rivaroxaban exhibited the same previously documented dose-proportional PK profile. Age and renal function moderately affected the PK profile, but variations were within the overall variability seen in the studies (Figure 3) [12]. Variations in gender and body weight had a minimal effect. Simulations of the approved rivaroxaban dosing regimen for VTE treatment (15 mg bid for 3 weeks followed by $20 \mathrm{mg}$ od) demonstrated that no fluctuations in $\mathrm{C}_{\max }$ would be expected during the transition from bid to od dosing (Figure 4). Co-administration of laxatives, diuretics, non-steroidal anti-inflammatory drugs and ASA did not significantly alter the PK profile of rivaroxaban, although use of concomitant strong CYP3A4 inducers reduced rivaroxaban exposure by up to $50 \%$ [12]. As seen for patients undergoing orthopaedic surgery, an almost linear correlation between rivaroxaban exposure and PT prolongation was demonstrated [12].

Dabigatran has been evaluated for the treatment of acute VTE in the RE-COVER and RE-COVER II clinical trials $[69,70]$. In these studies, patients received either parenteral anticoagulant followed by dabigatran $150 \mathrm{mg}$

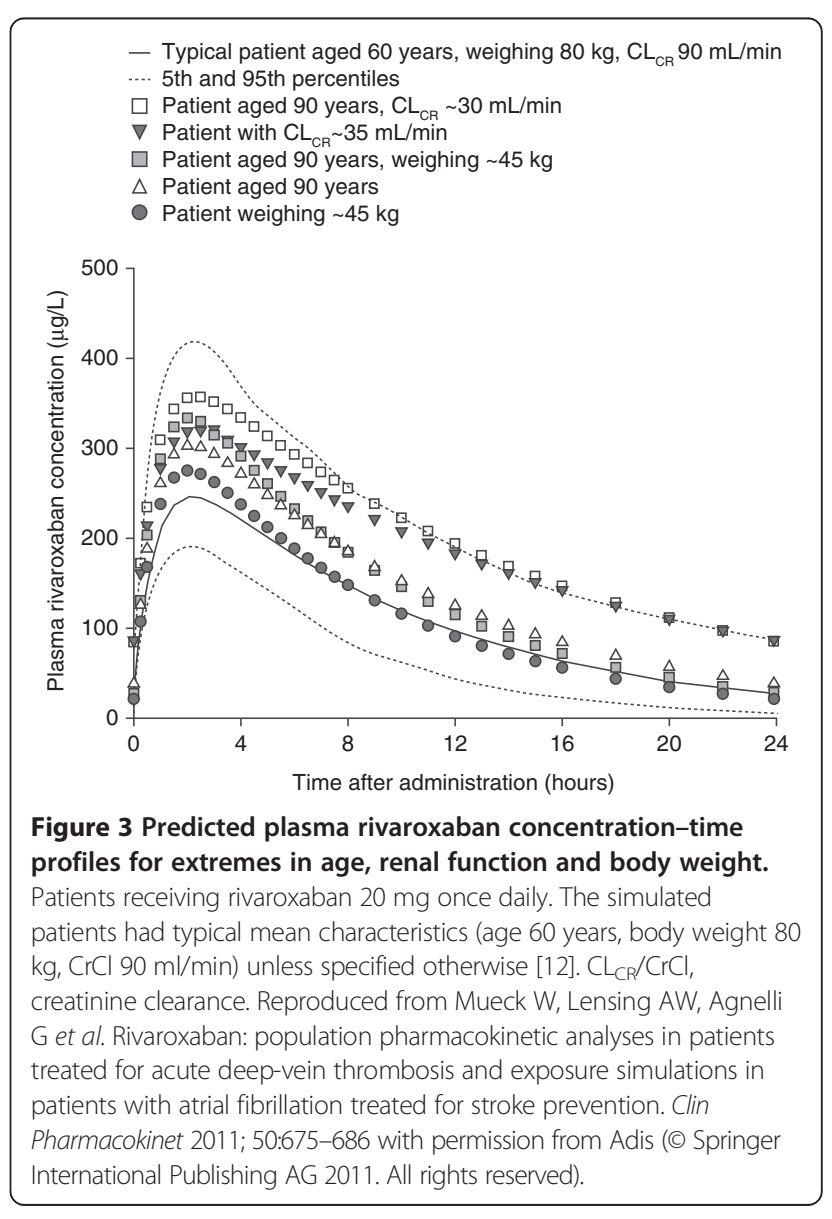




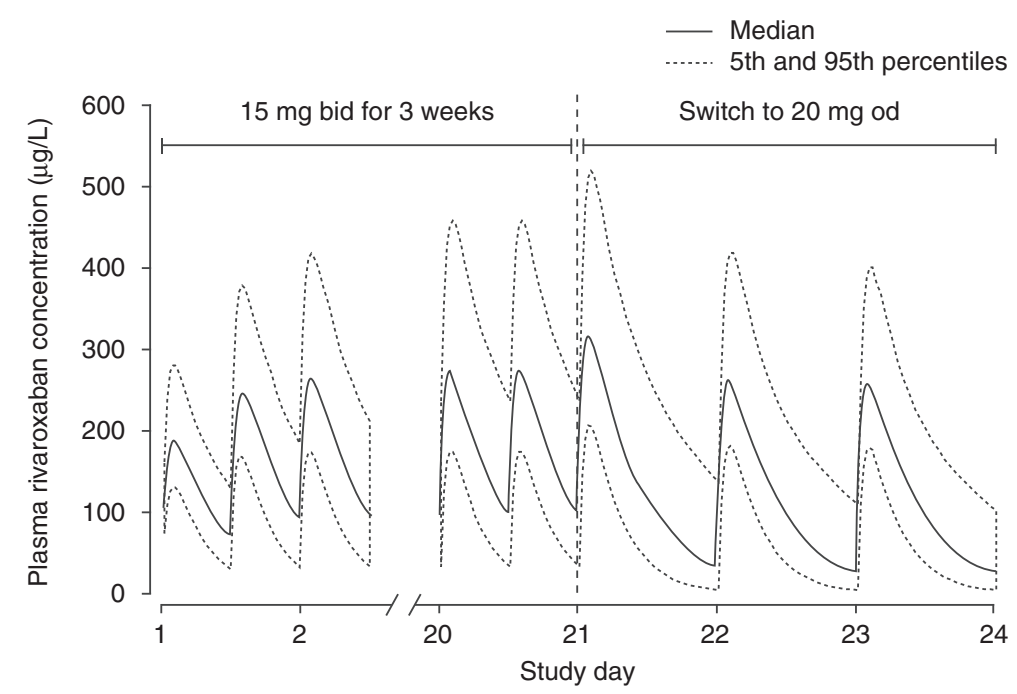

Figure 4 Simulated venous thromboembolism treatment dosing regimen of rivaroxaban. Regimen is 15 mg bid for 3 weeks followed by 20 mg od ( $n=870$ ) [12]. bid, twice daily; od, once daily. Reproduced from Mueck W, Lensing AW, Agnelli G et al. Rivaroxaban: population pharmacokinetic analyses in patients treated for acute deep-vein thrombosis and exposure simulations in patients with atrial fibrillation treated for stroke prevention. Clin Pharmacokinet 2011; 50:675-686 with permission from Adis (๑ Springer International Publishing AG 2011. All rights reserved).

bid or parenteral anticoagulant overlapping with a VKA until an international normalised ratio (INR) of 2-3 was achieved. The dual-drug regimen with dabigatran was shown to be as effective as standard therapy, with a similar safety profile. Two further studies have shown dabigatran $150 \mathrm{mg}$ bid to be effective for the long-term treatment of VTE, although the results of one study showed that dabigatran significantly increased the incidence of ACS compared with warfarin [71,72].

Apixaban is being evaluated for VTE treatment in two phase III clinical trials. The AMPLIFY study will compare apixaban $10 \mathrm{mg}$ bid for 7 days followed by $5 \mathrm{mg}$ bid with standard therapy for the treatment of acute VTE (www.clinicaltrials.gov; NCT00643201). AMPLIFYEXT evaluated apixaban $2.5 \mathrm{mg}$ bid or $5 \mathrm{mg}$ bid versus placebo for 12 months after initial treatment of VTE. The recently published results demonstrated a significant reduction in recurrent VTE with apixaban without an increase in major bleeding [73].

\section{Stroke prevention in patients with non-valvular atrial fibrillation}

Partially as a result of an ageing population, AF is now the most commonly occurring heart arrhythmia [74,75] and is a major risk factor for stroke [74]. The phase III ROCKET AF study showed that rivaroxaban (20 mg od) was noninferior to dose-adjusted VKA therapy in patients with AF for the prevention of stroke and systemic embolism, with similar rates of bleeding [76]. In the secondary efficacy analysis in the as-treated safety population, rivaroxaban demonstrated superiority compared with warfarin. Importantly, rates of intracranial haemorrhage were significantly lower with rivaroxaban, and the incidences of myocardial infarction, vascular death or all-cause mortality were numerically lower [76]. Observed rivaroxaban plasma concentrations (mean, 5/95 percentiles) are shown in Table 2. A population PK model for rivaroxaban in patients with AF was constructed based on data from the DVT treatment studies, taking into account the fact that AF populations are typically older than those undergoing orthopaedic surgery or requiring treatment for VTE [12]. A virtual population of 1000 elderly patients with AF was simulated; results indicated that the average $C_{\max }$ and AUC of rivaroxaban in patients with AF could be expected to be slightly higher $(7.4 \%$ for $C_{\text {max }} ; 15.3 \%$ for $\left.A U C\right)$ than values for patients with DVT [12]. Renal impairment was expected to lead to increased exposure [12]. These predictions were subsequently confirmed in a population PK analysis of the ROCKET AF dataset, which included data from 161 individuals. Apparent clearance and volume of distribution at steady state were estimated to be approximately $6 \mathrm{l} / \mathrm{h}$ and 80 litres, respectively, with moderate interindividual variability (Table 3). PK parameters for patients with moderate renal impairment given rivaroxaban $15 \mathrm{mg}$ od were generally similar to those estimated for patients with either no or mild renal impairment who received rivaroxaban $20 \mathrm{mg}$ od. Ratios of the means of $\mathrm{C}_{\max }$ and $\mathrm{AUC}$ for time 0 to 24 hours $\left(\mathrm{AUC}_{0-24}\right)$ were 0.88 and 0.91 , respectively, for patients with moderate renal impairment compared with those with mild impairment or normal renal function, and the distributions overlapped considerably, supporting the use of a reduced rivaroxaban 
$15 \mathrm{mg}$ od dose for patients with moderate renal impairment [I Girgis. Unpublished data]. In addition, modelling work supported the use of a lower rivaroxaban dose in Japanese patients with AF $[77,78]$, and in a phase III randomised study (J-ROCKET AF) a $15 \mathrm{mg}$ od dose was found to be non-inferior to warfarin (hazard ratio 1.11; 95\% confidence interval $0.87-1.42$ ) for the prevention of stroke and systemic embolism [79].

Dabigatran was evaluated for the prevention of stroke in patients with AF in the phase III RE-LY study. In RE-LY, dabigatran $150 \mathrm{mg}$ bid significantly reduced the risk of stroke or systemic embolism compared with warfarin, with a similar rate of major bleeding, whereas the $110 \mathrm{mg}$ bid dabigatran dose had similar efficacy to warfarin and with significantly lower rates of major bleeding $[80,81]$. Data from phase I and II studies of dabigatran in healthy subjects $(\mathrm{n}=128)$ and patients undergoing orthopaedic surgery or with AF $(n=2252)$ were used to construct a population PK model for dabigatran, which was then validated by comparison with PK data collected in RELY [82]. Given the high renal clearance of dabigatran, $\mathrm{CrCl}$ was built into the baseline assumptions for the model, and PD data were evaluated with the use of activated partial thromboplastin time (aPTT) assays. For the development of a PK model for dabigatran, a dataset was collated from 80 healthy volunteers (44\% of whom had some level of renal impairment) and 1965 patients [82]. For both patients and healthy controls, the PK of dabigatran was best described by a two-compartment model and there was a linear correlation between clearance and renal function. Age, gender and therapeutic indication (AF or orthopaedic surgery) influenced clearance, and body weight influenced volume of distribution [82]. The values predicted by the model agreed well with those observed in RE-LY, and there was a linear correlation between dabigatran exposure and aPTT prolongation. Using the data to simulate plasma concentration-time profiles at steady state for a typical male patient with AF (age 68 years, weight $80 \mathrm{~kg}, \mathrm{CrCl} 87 \mathrm{ml} / \mathrm{min}$ ) controlling for a variety of covariates, the effect remained within the overall variability for the average patient with AF, with the exception of renal impairment, which led to increases in exposure of $40 \%$ for a $\mathrm{CrCl}$ of $50 \mathrm{ml} / \mathrm{min}$ and $90 \%$ with a $\mathrm{CrCl}$ of $30 \mathrm{ml} / \mathrm{min}$. There was less peak-to-trough fluctuation with dabigatran dosing at $150 \mathrm{mg}$ bid than for $300 \mathrm{mg}$ od [82]. Further simulations of patients with moderate and severe renal impairment indicated that, compared with patients with moderate renal impairment $(\mathrm{CrCl}>30-$ $49 \mathrm{ml} / \mathrm{min}$ ) given dabigatran $150 \mathrm{mg}$ bid, those with severe impairment $(\mathrm{CrCl} 15-30 \mathrm{ml} / \mathrm{min})$ had a $35 \%$ higher average $C_{\max }$ with dabigatran $150 \mathrm{mg}$ od and a $42 \%$ lower average $C_{\text {trough }}$ with a dabigatran $75 \mathrm{mg}$ od dose. Dabigatran $75 \mathrm{mg}$ bid resulted in a reasonable matching of exposures [83].

\section{Secondary prevention of major cardiovascular events in patients with acute coronary syndrome}

In the recent phase III ATLAS ACS 2 TIMI 51 trial, rivaroxaban $2.5 \mathrm{mg}$ bid or $5 \mathrm{mg}$ bid was shown to significantly reduce the incidence of death, myocardial infarction or stroke compared with placebo when added to standard dual anti-platelet therapy (ASA plus either clopidogrel or ticlopidine) in patients with ACS [84]. Using data from the preceding phase II study, ATLAS ACS TIMI 46 [85], a population PK model was constructed to characterise the parameters of rivaroxaban in this population and model the effects of demographic variations on rivaroxaban PK [86]. Data from 2290 patients were used and the observed rivaroxaban plasma concentrations (mean, 5/95 percentiles) are shown in Table 2. As for the models in other patient populations, rivaroxaban PK was described by an oral one-compartment model. Apparent clearance and volume of distribution were approximately $6.5 \mathrm{l} / \mathrm{h}$ and 58 litres, respectively, with low-to-moderate interindividual variability. Variations in renal function, age and body weight on exposure were consistent with previous findings and PK parameters were similar to those estimated for other patient populations (Table 3) [86].

The phase III APPRAISE-2 trial of apixaban demonstrated that in high-risk patients after ACS the addition of apixaban $5 \mathrm{mg}$ bid to antiplatelet therapy increased rates of major bleeding without significantly reducing the rates of recurrent ischaemic events [87]. Dabigatran is not being investigated in phase III studies of patients with ACS.

\section{Laboratory monitoring of novel oral anticoagulants}

Because novel OACs competitively and directly inhibit specific factors of the coagulation cascade, their concentration-time profiles directly determine the time course of inhibition (taking into consideration fluctuations with absorption and elimination processes associated with oral dosing). This is in contrast to warfarin, which works indirectly by inhibiting components necessary for the synthesis of blood coagulation factors; therefore, inhibition by warfarin is determined by the half-life of synthesis. The predictable PK and PD profiles of rivaroxaban and other novel OACs mean that routine coagulation monitoring is not normally required [88]. However, in cases where an emergency intervention requires immediate assessment of anticoagulation, such as prior to urgent surgery, it may be useful or essential to be able to measure the anticoagulant effect of a novel OAC. Available tests can be divided into assays that measure general clot formation and those that directly quantify inhibition of a specific clotting factor. Owing to their modes of action, novel OACs affect some of these assays in different ways and an understanding of this is key to correctly interpreting results. 


\section{Clot-based assays}

The most commonly available clot-based assays include the PT, dilute PT, aPTT, ecarin clotting time (ECT), HepTest and prothrombinase-induced clotting time (PiCT) [89]. Each of these tests measures the time taken for a plasma sample to form a clot after the addition of calcium and an activator in the presence of the anticoagulant to be monitored. This means that they are not specific to any particular anticoagulant. The effects of rivaroxaban, dabigatran and apixaban on these tests are summarised in Table 4.

PT measures the time for plasma to clot after the addition of calcium and thromboplastin. The results are always given in seconds. Rivaroxaban prolongs PT in a dose-dependent manner but the extent of prolongation depends on the thromboplastin reagent used [90,91]. A multicentre study that evaluated the interlaboratory variability of PT measurements with rivaroxaban found that the use of local reagents led to greater variability than when all laboratories used a standardised Neoplastine CI Plus test (Diagnostica Stago, Asnières-sur-Seine, France), which had a higher sensitivity for rivaroxaban than many other PT assays [92]. Another group has also recently reported reproducible results with a calcium chloridemodified PT assay [93]. The variation in the sensitivity of different thromboplastin reagents is overcome for VKA monitoring by conversion to the INR, but this is specific to VKAs and cannot be used with rivaroxaban or the other novel OACs [91].

Even with standardisation, there are a number of other limitations of PT when applied to novel OACs $[89,90]$. The presence of concomitant systemic conditions, such as hepatic impairment, sepsis or vitamin K deficiency, can lead to a prolongation of PT. The PT is dependent on factors of the extrinsic coagulation pathway other than Factor $\mathrm{Xa}$ and it is not specific to any agent. Furthermore, the short half-life of, for example, rivaroxaban (5-13 hours) led to transient PT results, whereas for warfarin (half-life 36-42 hours) less variability can be expected. In addition, disappearance from the plasma of a Factor Xa inhibiting agent does not always correlate with a return to normal Factor Xa levels. Finally, PT reagents are insensitive at low concentrations of rivaroxaban $[89,90]$ and are not able to accurately measure the $C_{\text {trough }}$ levels predicted for rivaroxaban in PK models: $C_{\text {trough }}$ levels were in the range 9-32 ng/ml (Table 3 ) but Neoplastine Plus can only measure plasma levels down to approximately $50 \mathrm{ng} / \mathrm{ml}$, meaning that a PT reading taken around the time of $\mathrm{C}_{\text {trough }}$ will likely provide a false negative result [89]. These limitations also apply to dilute PT assays. Nevertheless, if used in an emergency and in the absence of any other available test, Neoplastine Plus (with results expressed in seconds) is the recommended agent for assessing the anticoagulant effect of rivaroxaban [3].
The aPTT test is performed in the absence of a tissue factor and, therefore, measures the overall function of the intrinsic coagulation pathway. Traditionally performed to monitor coagulation with unfractionated heparin, aPTT is performed by adding a contact activator (e.g. celite, ellagic acid, kaolin or silica) and cephalins to citrated plasma [89]. Calcium is added after a preincubation period and the clotting time is then measured. When using aPTT to assess rivaroxaban and apixaban, the test was less sensitive than PT, and results with dabigatran were non-linear at higher doses $[89,90]$. A recent study that tested a range of clotting assays with dabigatran suggested that aPTT could be used as a screening test for the risk of overdose but not for quantitative measurement of dabigatran [94].

HepTest is a clot-based anti-Factor Xa assay, in which a plasma sample is preincubated with bovine Factor Xa before addition of calcium chloride and thromboplastin. Rivaroxaban prolongs HepTest clotting time, although a shortened incubation time must be used with low concentrations to ensure a linear dose-response [91]. In contrast, ECT measures thrombin clotting using a derivative of snake venom to generate a prothrombin intermediate, and is thus likely to be more appropriate for monitoring dabigatran activity. Indeed, dabigatran prolongs ECT in a dose-dependent manner and can be calibrated to dabigatran concentrations [95]. The thrombin generation test is capable of assessing each phase of thrombin generation but may lack sensitivity [89], whereas another assay, Hemoclot, has been reported to have high sensitivity, good reproducibility and a linear dose correlation with dabigatran $[90,94]$. The PiCT test, which uses Factor Xa, phospholipids and a Factor $\mathrm{V}$ activator, is affected by both Factor $\mathrm{Xa}$ and thrombin inhibitors. Rivaroxaban and dabigatran prolong PiCT, although incubation should be avoided with rivaroxaban and human, rather than bovine, Factor Xa must be used [89]. However, as with many of the other tests described, a lack of sensitivity at low concentrations and variation between tests limit their usefulness for assessing novel OACs [89].

\section{Chromogenic assays}

Chromogenic assays measure the change in absorbance when a chromophore-tagged substrate of a specific clotting factor is cleaved by the coagulation factor to be measured, a process that is inhibited by the presence of the anticoagulant [89]. Such assays are more specific than clot-based assays and have proved suitable for quantitative measurement of rivaroxaban exposure with dosedependent results covering both the expected $C_{\max }$ and $\mathrm{C}_{\text {trough }}$ levels after therapeutic doses. Nevertheless, appropriate calibration over a wide range of plasma concentrations is required to create a standard reference doseresponse curve [89,90]. A recent ex vivo study evaluated the accuracy of three anti-Factor Xa chromogenic assays 
Table 4 Comparison and suitability of laboratory assays for monitoring novel oral anticoagulants $[89,90]$

\begin{tabular}{|c|c|c|c|c|c|c|c|c|c|}
\hline Agent & PT & $\begin{array}{l}\text { Dilute } \\
\text { PT }\end{array}$ & aPTT & ECT & HepTest & PiCT & $\begin{array}{l}\text { Chromogenic } \\
\text { assays }\end{array}$ & Preferred assay & $\begin{array}{l}\text { Assays that may } \\
\text { be used in the } \\
\text { absence of } \\
\text { preferred assay }\end{array}$ \\
\hline Rivaroxaban & $\begin{array}{l}\text { Dose-dependent } \\
\text { prolongation but } \\
\text { results vary with } \\
\text { thromboplastin reagent }\end{array}$ & $\begin{array}{l}\text { Results } \\
\text { vary as } \\
\text { for PT }\end{array}$ & $\begin{array}{c}\text { Not as sensitive as } \\
\text { PT }\end{array}$ & NA & $\begin{array}{l}\text { Dose-dependent } \\
\text { response with short } \\
\text { incubation time }\end{array}$ & $\begin{array}{c}\text { Sensitive if } \\
\text { incubation } \\
\text { avoided and } \\
\text { human Factor Xa } \\
\text { used }\end{array}$ & $\begin{array}{l}\text { Dose-dependent } \\
\text { response with } \\
\text { human Factor Xa } \\
\text { and buffer }\end{array}$ & $\begin{array}{c}\text { Factor Xa } \\
\text { chromogenic assay } \\
\text { (with appropriate } \\
\text { calibration) }\end{array}$ & PT (Neoplastin) \\
\hline Apixaban & $\begin{array}{l}\text { Prolongs PT but results } \\
\text { may vary with } \\
\text { thromboplastin reagent }\end{array}$ & $\begin{array}{l}\text { More } \\
\text { sensitive } \\
\text { than PT }\end{array}$ & $\begin{array}{c}\text { Other tests may be } \\
\text { more sensitive }\end{array}$ & NA & $\begin{array}{l}\text { Dose-dependent } \\
\text { response and more } \\
\text { sensitive than PT, dilute } \\
\text { PT and aPTT }\end{array}$ & NR & $\begin{array}{l}\text { Dose-dependent } \\
\text { response }\end{array}$ & $\begin{array}{l}\text { Rotachrom }{ }^{\circledR} \text { Factor Xa } \\
\text { chromogenic assay } \\
\text { (with appropriate } \\
\text { calibration) }\end{array}$ & Modified PT \\
\hline Dabigatran & $\begin{array}{c}\text { Prolongs PT but } \\
\text { insensitive and results } \\
\text { may vary with } \\
\text { thromboplastin reagent }\end{array}$ & NR & $\begin{array}{l}\text { More sensitive than } \\
\text { PT but results vary } \\
\text { with different } \\
\text { reagents }\end{array}$ & $\begin{array}{l}\text { Prolongs ECT } \\
\text { in a dose- } \\
\text { dependent } \\
\text { manner }\end{array}$ & $\begin{array}{l}\text { Prolongs HepTest but } \\
\text { may be unsuitable }\end{array}$ & $\begin{array}{l}\text { Prolongs PiCT but } \\
\text { insensitive at } \\
\text { lower doses }\end{array}$ & In development & Hemoclot suggested & $\mathrm{ECT}, \mathrm{aPTT}$ \\
\hline
\end{tabular}


for measuring rivaroxaban concentrations using plasma samples from healthy subjects and patients [96]. Assays that did and did not include exogenous antithrombin, with two different concentration calibration sets for each, were investigated. All assays showed a linear relationship between actual rivaroxaban concentrations and the optical density of the chromogenic assays. However, although the non-antithrombin assays were able to provide accurate results over a wide range of rivaroxaban concentrations, the assay that contained exogenous antithrombin provided falsely elevated results, suggesting that it is unsuitable for use with rivaroxaban [96].

A recent field trial investigated the inter-laboratory viability of the measurement of rivaroxaban plasma concentrations with anti-Factor Xa chromogenic assays. The study was conducted in 24 laboratories in Europe and North America using standardised rivaroxaban calibrators and plasma control samples [97]. Each centre used both the centrally provided modified STA ${ }^{\circledR}$ Rotachrom ${ }^{\circledR}$ assay (Diagnostica Stago) and local Factor Xa reagents to perform tests on a variety of sample concentrations. Using the centrally provided assay, a lower interlaboratory variation was found compared with when local reagents were employed, with the greatest difference found at lower concentrations of rivaroxaban. This study suggests that, using standard calibrators and controls, a range of rivaroxaban plasma concentrations (20$660 \mathrm{ng} / \mathrm{ml}$ ), which covers the expected rivaroxaban plasma levels after therapeutic doses, could be measured using the chromogenic anti-Factor Xa assay STA Rotachrom [97]. This assay could provide a more sensitive and specific alternative to the previously described PT method for the measurement of rivaroxaban plasma concentrations. The STA Rotachrom assay and two other chromogenic assays, Biophen $\mathrm{DiXaI}^{\circledR}$ (Hyphen Biomed) and Technochrom ${ }^{\circledR}$ anti-Xa (Technoclone), have received European authorisation for commercial distribution. STA Rotachrom has been identified as the preferred assay for measuring the activity of apixaban [5]. Chromogenic assays to measure dabigatran are currently in development.

\section{Discussion}

Of the three currently licensed novel OACs, the PK and PD profile of rivaroxaban is arguably the most fully elucidated. Observations in phase I and phase II studies have shown that rivaroxaban has predictable, doseproportional PK with an anticoagulant effect that also increases in a linear fashion with increasing plasma concentration; importantly, this profile is largely consistent in the presence or absence of demographic variations [22]. Although characterisation of PK in healthy subjects is important, it is vital to understand how a drug is likely to behave in actual patient populations. The use of population PK modelling is an invaluable tool for achieving full PK and PD characterisation. There is now a substantial body of patient modelling data published for rivaroxaban and dabigatran, although this is currently lacking for apixaban. One advantage of PK modelling is that it can be used to simulate 'extreme' scenarios, such as those that present in patients who are elderly, have renal or hepatic impairment, or who are obese. The models described herein show that, for the most part, the PK and PD profiles of rivaroxaban and dabigatran remain within acceptable boundaries for most individual patients, supporting the use of fixed dosing regimens $[11,12,52,57,82]$. Overall, both agents exhibit only moderate $\mathrm{PK} / \mathrm{PD}$ variability, which contrasts with the unpredictable interindividual variations seen with warfarin that necessitate routine coagulation monitoring.

The other novel OACs also exhibit similarly predictable profiles, but some comparative PK properties differ in ways that may be important to consider in a given clinical situation. For example, the high renal clearance of dabigatran $(80 \%)$ means that it is not considered suitable in the EU for patients with severe renal insufficiency $(\mathrm{CrCl} 15-<30 \mathrm{ml} / \mathrm{min})[6]$, although it can be used for the prevention of stroke in severely renally impaired patients with AF in the US (at a reduced $75 \mathrm{mg}$ od dose) [8]. Rivaroxaban and apixaban, which are eliminated in greater proportions via other non-renal routes, may be used with caution in the relevant licensed indication in such patients $[3,5]$. Equally, the drug interaction profile of each agent may be an important consideration if a patient is taking concomitant medications. Rivaroxaban should not be used in conjunction with strong inhibitors of both CYP3A4 and Pgp, such as azole-antimycotics (e.g. ketoconazole, itraconazole, voriconazole and posaconazole) or HIV protease inhibitors (e.g. ritonavir) because competitive elimination with rivaroxaban will increase exposure to the latter to a clinically relevant degree $[3,35]$. However, comedication with strong inhibitors of one of these pathways only, or moderate inhibitors of both, may be considered with caution. In contrast, dabigatran is not metabolised via CYP3A4 pathways but should not be co-administered with potent P-gp inhibitors (e.g. amiodarone) [6], and apixaban should not be given in conjunction with strong CYP3A4 inhibitors but is not affected by competition for P-gp transport [5].

An important observation derived from population PK modelling is the effect of renal clearance and age on the $\mathrm{PK} / \mathrm{PD}$ profiles of rivaroxaban and dabigatran. These two parameters are often linked because renal efficiency decreases with advancing age. Results of PK modelling with dabigatran led to recommendations for a reduced dose of $150 \mathrm{mg}$ od to be used for VTE prevention in patients with moderate renal impairment $(\mathrm{CrCl} 30-49 \mathrm{ml} /$ min) $[6,83]$. Rivaroxaban modelling confirmed that no 
dose reduction is needed for patients with $\mathrm{CrCl} \mathrm{15-}$ $49 \mathrm{ml} / \mathrm{min}$ (moderate or severe renal impairment) receiving the $10 \mathrm{mg}$ dose approved for VTE prevention after elective hip and knee replacement surgery. For the treatment of DVT in patients with $\mathrm{CrCl} 15-49 \mathrm{ml} / \mathrm{min}$, rivaroxaban PK modelling supported the recommended $15 \mathrm{mg}$ bid dose for the acute phase (first 21 days) of therapy and a reduced dose of rivaroxaban $15 \mathrm{mg}$ od for the extended treatment phase (post-day 21). For the prevention of stroke and systemic embolism in patients with non-valvular $\mathrm{AF}$ and $\mathrm{CrCl}<50 \mathrm{ml} / \mathrm{min}$, the reduced dose of rivaroxaban $15 \mathrm{mg}$ od was supported by phase III trial data $(\mathrm{CrCl} 30-49 \mathrm{ml} / \mathrm{min}$; moderate renal impairment) and modelling $(\mathrm{CrCl} 15-<30 \mathrm{ml} / \mathrm{min}$; severe renal impairment) [3,76]. Given that data are limited, rivaroxaban should be used with caution in patients with $\mathrm{CrCl} 15-<30 \mathrm{ml} / \mathrm{min}$ in all settings [3].

Although not routinely required, laboratory testing of anticoagulant activity may sometimes be necessary when employing novel OACs. Because of the PK/PD properties of these agents, few clot-based assays are appropriate for this task, and in general there is a lack of standardised calibration and methodology for conducting these tests with the novel OACs $[90,95]$. This contrasts to the case with warfarin, for which cumulative years of experience have led to a standardised calibration of PT test results using the INR. At clinically relevant plasma concentrations of rivaroxaban, the effect on PT prolongation is small and short-lived, and the test has a low sensitivity for all novel OACs $[90,95]$. However, the advantage of PT is that it is a standard test that is available and can be performed rapidly in most clinical laboratories worldwide [92]. Chromogenic assays that respond to specific coagulation factors are now available and can provide specific, sensitive and accurate quantitative measurement of rivaroxaban exposure within the expected range of plasma concentration seen with therapeutic doses $[90,95]$.

For this reason, approved chromogenic assays should be regarded as the gold standard for measuring rivaroxaban plasma levels under the unusual circumstances where this may be required. It is important to note that, regardless of the assay used, the result will provide an indication of drug plasma levels but not a direct measurement of anticoagulation. Therefore, chromogenic assays should only be used to establish the presence or absence of the drug in plasma; the potential influence of the time of drug administration should be taken into consideration when interpreting the results. This differs from INR monitoring for VKAs where a safe and effective range is targeted and the INR results ultimately drive treatment decisions. With the anticipated increase in the use of novel OACs, laboratories should familiarise themselves with chromogenic assays and how the results should be interpreted.

\section{Conclusions}

Rivaroxaban and dabigatran (and apixaban based on such data as have been published) have predictable PK and PD properties allowing for fixed oral dosing regimens to be followed regardless of demographic variations without the need for routine coagulation monitoring in most cases. The relatively short half-life of these drugs and the direct correlation between concentration-time profile and inhibition are advantages for fast offset of action when treatment is stopped. In circumstances where the measurement of plasma concentration is required, the use of standardised calibrators and controls is essential to obtaining accurate data - this appears possible with anti-Factor Xa chromogenic assays for rivaroxaban and apixaban, and HemoClot, ECT or aPTT for dabigatran. However, it is important that the results of any of these assays are interpreted within the context of the time of drug administration.

\section{Abbreviations}

ACS: Acute coronary syndrome; AF: Atrial fibrillation; aPTT: Activated partial thromboplastin time; ASA: Acetylsalicylic acid; AUC: Area under the concentration-time curve; bid: Twice daily; $\mathrm{CrCl}$ : Creatinine clearance; CYP: Cytochrome P450; DVT: Deep vein thrombosis; ECT: Ecarin clotting time; INR: International normalised ratio; OAC: Oral anticoagulant; od: Once daily; P-gp: P-glycoprotein; PD: Pharmacodynamic; PiCT: Prothrombinase-induced clotting time; PK: Pharmacokinetic; PE: Pulmonary embolism; PT: Prothrombin time; THR: Total hip replacement; TKR: Total knee replacement; VKA: Vitamin K antagonist; VTE: Venous thromboembolism.

\section{Competing interests}

The authors are employees of Bayer HealthCare Pharmaceuticals, the manufacturers of rivaroxaban.

\section{Authors' contributions}

All authors contributed to the drafting and review of the manuscript, and read and approved the final manuscript.

\section{Acknowledgements}

The authors would like to acknowledge Stephen Purver, who provided medical writing services with funding from Bayer HealthCare

Pharmaceuticals and Janssen Scientific Affairs, LLC.

Received: 1 March 2013 Accepted: 9 June 2013

Published: 28 June 2013

\section{References}

1. Ansell J, Hirsh J, Hylek E, Jacobson A, Crowther M, Palareti G: Pharmacology and management of the vitamin $\mathrm{K}$ antagonists: American College of Chest Physicians evidence-based clinical practice guidelines (8th Edition). Chest 2008, 133:160S-198S.

2. Ageno W, Gallus AS, Wittkowsky A, Crowther M, Hylek EM, Palareti G: Oral anticoagulant therapy: antithrombotic therapy and prevention of thrombosis, 9th ed: American College of Chest Physicians evidencebased clinical practice guidelines. Chest 2012, 141:e44S-e88S.

3. Bayer Pharma AG: Xarelto ${ }^{\circledR}$ (rivaroxaban) summary of product characteristics. 2013. http://www.ema.europa.eu/docs/en_GB/ document_library/EPAR_-_Product_Information/human/000944/ WC500057108.pdf.

4. Janssen Pharmaceuticals Inc: Xarelto ${ }^{\circledR}$ (rivaroxaban) prescribing information. 2013. http://www.accessdata.fda.gov/drugsatfda_docs/label/ 2013/022406s004lbl.pdf.

5. Bristol-Myers S, Pfizer EEIG: Eliquis ${ }^{\circledR}$ (apixaban) summary of product characteristics. 2013. http://www.ema.europa.eu/docs/en_GB/ document_library/EPAR___Product_Information/human/002148/ WC500107728.pdf. 
6. Boehringer Ingelheim International $\mathrm{GmbH}$ : Pradaxa $^{\circledR}$ (dabigatran etexilate) summary of product characteristics. 2013. http://www.emea.europa.eu/ docs/en_GB/document_library/EPAR_-_Product_Information/human/ 000829/WC500041059.pdf.

7. Bristol-Myers Squibb Company, Pfizer Inc: Eliquis ${ }^{\circledR}$ (apixaban) prescribing information. 2012. http://www.accessdata.fda.gov/drugsatfda_docs/label/ 2012/202155s000lbl.pdf.

8. Boehringer Ingelheim Pharmaceuticals Inc: Pradaxa ${ }^{\circledR}$ (dabigatran etexilate) prescribing information. 2013. http://www.accessdata.fda.gov/ drugsatfda docs/label/2013/022512s017lbl.pdf.

9. Samama MM: The mechanism of action of rivaroxaban - an oral, direct Factor Xa inhibitor - compared with other anticoagulants. Thromb Res 2011, 127:497-504.

10. Perzborn E, Roehrig S, Straub A, Kubitza D, Misselwitz F: The discovery and development of rivaroxaban, an oral, direct Factor Xa inhibitor. Nature Reviews Drug Discovery 2011, 10:61-75.

11. Mueck W, Borris LC, Dahl OE, Haas S, Huisman MV, Kakkar AK, Kälebo P, Muelhofer E, Misselwitz F, Eriksson Bl: Population pharmacokinetics and pharmacodynamics of once- and twice-daily rivaroxaban for the prevention of venous thromboembolism in patients undergoing total hip replacement. Thromb Haemost 2008, 100:453-461.

12. Mueck W, Lensing AW, Agnelli G, Decousus H, Prandoni P, Misselwitz F: Rivaroxaban: population pharmacokinetic analyses in patients treated for acute deep-vein thrombosis and exposure simulations in patients with atrial fibrillation treated for stroke prevention. Clin Pharmacokinet 2011, 50:675-686.

13. Spyropoulos AC: Investigational treatments of venous thromboembolism. Expert Opin Investig Drugs 2007, 16:431-440.

14. Hoffman M, Monroe DM: Coagulation 2006: a modern view of hemostasis. Hematol Oncol Clin North Am 2007, 21:1-11.

15. Perzborn E, Roehrig S, Straub A, Kubitza D, Mueck W, Laux V: Rivaroxaban: a new oral Factor Xa inhibitor. Arterioscler Thromb Vasc Biol 2010, 30:376-381.

16. Turpie AGG: Oral, direct Factor Xa inhibitors in development for the prevention and treatment of thromboembolic diseases. Arterioscler Thromb Vasc Biol 2007, 27:1238-1247.

17. Kubitza D, Becka M, Voith B, Zuehlsdorf M, Wensing G: Safety, pharmacodynamics, and pharmacokinetics of single doses of BAY 59-7939, an oral, direct Factor Xa inhibitor. Clin Pharmacol Ther 2005, 78:412-421.

18. Weinz C, Buetehorn U, Daehler HP, Kohlsdorfer C, Pleiss U, Sandmann S, Schlemmer KH, Schwarz T, Steinke W: Pharmacokinetics of BAY 59-7939 - an oral, direct Factor Xa inhibitor - in rats and dogs. Xenobiotica 2005, 35:891-910.

19. Weinz C, Schwarz T, Kubitza D, Mueck W, Lang D: Metabolism and excretion of rivaroxaban, an oral, direct Factor Xa inhibitor, in rats, dogs and humans. Drug Metab Dispos 2009, 37:1056-1064.

20. Sanofi-Aventis: Clexane (enoxaparin sodium) summary of product characteristics. 2011. http://www.sanofi-aventis.co.uk/products/ Clexane SPC.pdf.

21. Kubitza D, Becka M, Wensing G, Voith B, Zuehlsdorf M: Safety, pharmacodynamics, and pharmacokinetics of BAY 59-7939 - an oral, direct Factor Xa inhibitor - after multiple dosing in healthy male subjects. Eur J Clin Pharmacol 2005, 61:873-880.

22. Mueck W, Becka M, Kubitza D, Voith B, Zuehlsdorf M: Population model of the pharmacokinetics and pharmacodynamics of rivaroxaban - an oral, direct Factor Xa inhibitor - in healthy subjects. Int J Clin Pharmacol Ther 2007, 45:335-344.

23. Raghavan N, Frost CE, Yu Z, He K, Zhang H, Humphreys WG, Pinto D, Chen S, Bonacorsi S, Wong PC, Zhang D: Apixaban metabolism and pharmacokinetics after oral administration to humans. Drug Metab Dispos 2009, 37:74-81.

24. Stangier J: Clinical pharmacokinetics and pharmacodynamics of the oral direct thrombin inhibitor dabigatran etexilate. Clin Pharmacokinet 2008, 47:285-295

25. Blech S, Ebner T, Ludwig-Schwellinger E, Stangier J, Roth W: The metabolism and disposition of the oral direct thrombin inhibitor, dabigatran, in humans. Drug Metab Dispos 2008, 36:386-399.

26. Kubitza D, Becka M, Zuehlsdorf M, Mueck W: Body weight has limited influence on the safety, tolerability, pharmacokinetics, or pharmacodynamics of rivaroxaban (BAY 59-7939) in healthy subjects. J Clin Pharmacol 2007, 47:218-226.

27. Kubitza D, Becka M, Roth A, Mueck W: Dose-escalation study of the pharmacokinetics and pharmacodynamics of rivaroxaban in healthy elderly subjects. Curr Med Res Opin 2008, 24:2757-2765.
28. Kubitza D, Becka M, Roth A, Mueck W: The influence of age and gender on the pharmacokinetics and pharmacodynamics of rivaroxaban - an oral, direct Factor Xa inhibitor. J Clin Pharmacol 2013, 53:249-255.

29. Jiang J, Hu Y, Zhang J, Yang J, Mueck W, Kubitza D, Bauer RJ, Meng L, Hu P: Safety, pharmacokinetics and pharmacodynamics of single doses of rivaroxaban - an oral, direct Factor Xa inhibitor - in elderly Chinese subjects. Thromb Haemost 2010, 103:234-241.

30. Zhao X, Sun P, Zhou Y, Liu Y, Zhang H, Mueck W, Kubitza D, Bauer RJ, Zhang H, Cui Y: Safety, pharmacokinetics and pharmacodynamics of single/multiple doses of the oral, direct Factor Xa inhibitor rivaroxaban in healthy Chinese subjects. Br J Clin Pharmacol 2009, 68:77-88.

31. Kubitza D, Roth A, Becka M, Alatrach A, Halabi A, Hinrichsen H, Mueck W: Effect of hepatic impairment on the pharmacokinetics and pharmacodynamics of a single dose of rivaroxaban - an oral, direct Factor Xa inhibitor. Br J Clin Pharmacol 2013, 76:89-98.

32. Kubitza D, Becka M, Mueck W, Halabi A, Maatouk H, Klause N, Lufft V, Wand DD, Philipp T, Bruck H: Effects of renal impairment on the pharmacokinetics, pharmacodynamics and safety of rivaroxaban, an oral, direct Factor Xa inhibitor. Br J Clin Pharmacol 2010, 70:703-712.

33. Kubitza D, Becka M, Zuehlsdorf M, Mueck W: Effect of food, an antacid, and the $\mathrm{H} 2$ antagonist ranitidine on the absorption of BAY 59-7939 (rivaroxaban), an oral, direct Factor Xa inhibitor, in healthy subjects. J Clin Pharmacol 2006, 46:549-558.

34. Stampfuss J, Kubitza D, Becka M, Mueck W: The effect of food on the absorption and pharmacokinetics of rivaroxaban. Int J Clin Pharmacol Ther 2013, 51:549-561.

35. Mueck W, Kubitza D, Becka M: Co-administration of rivaroxaban with drugs that share its elimination pathways: pharmacokinetic effects in healthy subjects. Br J Clin Pharmacol 2013. doi:10.1111/bcp.12075.

36. Kubitza D, Becka M, Schwers S, Voith B: Investigation of pharmacodynamic and pharmacokinetic interactions between rivaroxaban and enoxaparin in healthy male subjects. Clinical Pharmacology in Drug Development 2013. doi:10.1002/cpdd.26.

37. Kubitza D, Becka M, Mueck W, Schwers S: Effect of co-administration of rivaroxaban and clopidogrel on bleeding time, pharmacodynamics and pharmacokinetics: a phase I study. Pharmaceuticals 2012, 5:279-296.

38. Kubitza D, Becka M, Mueck W, Zuehlsdorf M: Rivaroxaban- a novel, oral, direct Factor Xa inhibitor- has no clinically relevant interaction with acetylsalicylic acid or naproxen. [abstract]. J Thromb Haemost 2007, 5(Suppl 2):Abstract P-T-659.

39. Kubitza D, Becka M, Mueck W, Zuehlsdorf M: Safety, tolerability, pharmacodynamics, and pharmacokinetics of rivaroxaban - an oral, direct Factor Xa inhibitor - are not affected by aspirin. J Clin Pharmacol 2006, 46:981-990.

40. Härtter S, Koenen-Bergmann M, Sharma A, Nehmiz G, Lemke U, Timmer W Reilly PA: Decrease in the oral bioavailability of dabigatran etexilate after co-medication with rifampicin. Br J Clin Pharmacol 2012, 74:490-500.

41. Geerts WH, Bergqvist D, Pineo GF, Heit JA, Samama CM, Lassen MR, Colwell CW: Prevention of venous thromboembolism: American College of Chest Physicians evidence-based clinical practice guidelines (8th Edition). Chest 2008, 133:381S-453S.

42. Eriksson BI, Borris LC, Friedman RJ, Haas S, Huisman MV, Kakkar AK, Bandel TJ, Beckmann H, Muehlhofer E, Misselwitz F, Geerts W, RECORD1 Study Group: Rivaroxaban versus enoxaparin for thromboprophylaxis after hip arthroplasty. N Engl J Med 2008, 358:2765-2775.

43. Kakkar AK, Brenner B, Dahl OE, Eriksson BI, Mouret P, Muntz J, Soglian AG, Pap AF, Misselwitz F, Haas S, RECORD2 Investigators: Extended duration rivaroxaban versus short-term enoxaparin for the prevention of venous thromboembolism after total hip arthroplasty: a double-blind, randomised controlled trial. Lancet 2008, 372:31-39.

44. Lassen MR, Ageno W, Borris LC, Lieberman JR, Rosencher N, Bandel TJ, Misselwitz F, Turpie AGG, RECORD3 Investigators: Rivaroxaban versus enoxaparin for thromboprophylaxis after total knee arthroplasty. $N$ Engl J Med 2008, 358:2776-2786.

45. Turpie AGG, Lassen MR, Davidson BL, Bauer KA, Gent M, Kwong LM, Cushner FD, Lotke PA, Berkowitz SD, Bandel TJ, Benson A, Misselwitz F, Fisher WD, RECORD4 Investigators: Rivaroxaban versus enoxaparin for thromboprophylaxis after total knee arthroplasty (RECORD4): a randomised trial. Lancet 2009, 373:1673-1680.

46. Eriksson BI, Kakkar AK, Turpie AGG, Gent M, Bandel TJ, Homering M, Misselwitz F, Lassen MR: Oral rivaroxaban for the prevention of 
symptomatic venous thromboembolism after elective hip and knee replacement. J Bone Joint Surg Br 2009, 91:636-644.

47. Turpie AGG, Lassen MR, Eriksson Bl, Gent M, Berkowitz SD, Misselwitz F, Bandel TJ, Homering M, Westermeier T, Kakkar AK: Rivaroxaban for the prevention of venous thromboembolism after hip or knee arthroplasty. Pooled analysis of four studies. Thromb Haemost 2011, 105:444-453.

48. Eriksson BI, Borris LC, Dahl OE, Haas S, Huisman MV, Kakkar AK, Misselwitz F, Muehlhofer E, Kälebo P: Dose-escalation study of rivaroxaban (BAY 597939) - an oral, direct Factor Xa inhibitor - for the prevention of venous thromboembolism in patients undergoing total hip replacement. Thromb Res 2007, 120:685-693.

49. Eriksson Bl, Borris L, Dahl OE, Haas S, Huisman MV, Kakkar AK, Misselwitz F, Kälebo P, ODIXa-HIP Study Investigators: Oral, direct Factor Xa inhibition with BAY 59-7939 for the prevention of venous thromboembolism after total hip replacement. J Thromb Haemost 2006, 4:121-128.

50. Turpie AGG, Fisher WD, Bauer KA, Kwong LM, Irwin MW, Kälebo P, Misselwitz F, Gent M, ODXla-Knee Study Group: BAY 59-7939: an oral, direct Factor Xa inhibitor for the prevention of venous thromboembolism in patients after total knee replacement. A phase II dose-ranging study. J Thromb Haemost 2005, 3:2479-2486.

51. Eriksson BI, Borris LC, Dahl OE, Haas S, Huisman MV, Kakkar AK, Muehlhofer E, Dierig C, Misselwitz F, Kälebo P, ODIXa-HIP Study Investigators: A once-daily, oral, direct Factor Xa inhibitor, rivaroxaban (BAY 59-7939), for thromboprophylaxis after total hip replacement. Circulation 2006, 114:2374-2381.

52. Mueck W, Eriksson BI, Bauer KA, Borris L, Dahl OE, Fisher WD, Gent M, Haas S, Huisman MV, Kakkar AK, Kälebo P, Kwong LM, Misselwitz F, Turpie AGG: Population pharmacokinetics and pharmacodynamics of rivaroxaban an oral, direct Factor Xa inhibitor - in patients undergoing major orthopaedic surgery. Clin Pharmacokinet 2008, 47:203-216.

53. Eriksson BI, Dahl OE, Rosencher N, Kurth AA, van Dijk CN, Frostick SP, Kälebo P, Christiansen AV, Hantel S, Hettiarachchi R, Schnee J, Büller HR, RE-MODEL Study Group: Oral dabigatran etexilate vs. subcutaneous enoxaparin for the prevention of venous thromboembolism after total knee replacement: the RE-MODEL randomized trial. J Thromb Haemost 2007, 5:2178-2185.

54. RE-MOBILIZE The Writing Committee: Oral thrombin inhibitor dabigatran etexilate vs North American enoxaparin regimen for prevention of venous thromboembolism after knee arthroplasty surgery. J Arthroplasty 2009, 24:1-9.

55. Eriksson BI, Dahl OE, Rosencher N, Kurth AA, van Dijk CN, Frostick SP, Prins MH, Hettiarachchi R, Hantel S, Schnee J, Büller HR: Dabigatran etexilate versus enoxaparin for prevention of venous thromboembolism after total hip replacement: a randomised, double-blind, non-inferiority trial. Lancet 2007, 370:949-956.

56. Eriksson BI, Dahl OE, Huo MH, Kurth AA, Hantel S, Hermansson K, Schnee JM, Friedman RJ: Oral dabigatran versus enoxaparin for thromboprophylaxis after primary total hip arthroplasty (RE-NOVATE II). A randomised, doubleblind, non-inferiority trial. Thromb Haemost 2011, 105:721-729.

57. Troconiz IF, Tillmann C, Liesenfeld KH, Schafer HG, Stangier J: Population pharmacokinetic analysis of the new oral thrombin inhibitor dabigatran etexilate (BIBR 1048) in patients undergoing primary elective total hip replacement surgery. J Clin Pharmacol 2007, 47:371-382.

58. Lassen MR, Raskob GE, Gallus A, Pineo G, Chen D, Portman RJ: Apixaban or enoxaparin for thromboprophylaxis after knee replacement. N Engl J Med 2009, 361:594-604.

59. Lassen MR, Raskob GE, Gallus A, Pineo G, Chen D, Hornick P, the ADVANCE2 investigators: Apixaban versus enoxaparin for thromboprophylaxis after knee replacement (ADVANCE-2): a randomised double-blind trial. Lancet 2010, 375:807-815

60. Lassen MR, Gallus A, Raskob GE, Pineo G, Chen D, Ramirez LM, ADVANCE-3 Investigators: Apixaban versus enoxaparin for thromboprophylaxis after hip replacement. N Engl J Med 2010, 363:2487-2498.

61. Cohen AT, Agnelli G, Anderson FA, Arcelus JI, Bergqvist D, Brecht JG, Greer IA, Heit JA, Hutchinson JL, Kakkar AK, Mottier D, Oger E, Samama MM, Spannagl M, VTE Impact Assessment Group in Europe (VITAE): Venous thromboembolism (VTE) in Europe. The number of VTE events and associated morbidity and mortality. Thromb Haemost 2007, 98:756-764.

62. Heit JA, Cohen AT, Anderson FA, on behalf of the VTE Impact Assessment Group: Estimated annual number of incident and recurrent, non-fatal and fatal venous thromboembolism (VTE) events in the US [abstract]. Blood (ASH Annual Meeting Abstracts) 2005, 106. Abstract 910.

63. The EINSTEIN Investigators: Oral rivaroxaban for symptomatic venous thromboembolism. N Engl J Med 2010, 363:2499-2510.
64. The EINSTEIN-PE Investigators: Oral rivaroxaban for the treatment of symptomatic pulmonary embolism. N Engl J Med 2012, 366:1287-1297.

65. Fiessinger JN, Huisman MV, Davidson BL, Bounameaux H, Francis CW, Eriksson H, Lundström T, Berkowitz SD, Nyström P, Thorsén M, Ginsberg JS, THRIVE Treatment Study Investigators: Ximelagatran vs low-molecular-weight heparin and warfarin for the treatment of deep vein thrombosis: a randomized trial. JAMA 2005, 293:681-689.

66. van Gogh Investigators, Büller HR, Cohen AT, Davidson B, Decousus H, Gallus AS, Gent M, Pillion G, Piovella F, Prins MH, Raskob GE: Idraparinux versus standard therapy for venous thromboembolic disease. $N$ Engl $J$ Med 2007, 357:1094-1104.

67. Büller HR, Lensing AW, Prins MH, Agnelli G, Cohen A, Gallus AS, Misselwitz F, Raskob G, Schellong S, Segers A, Einstein-DVT Dose-Ranging Study investigators: A dose-ranging study evaluating once-daily oral administration of the Factor Xa inhibitor rivaroxaban in the treatment of patients with acute symptomatic deep vein thrombosis. The EINSTEINDVT dose-ranging study. Blood 2008, 112:2242-2247.

68. Agnelli G, Gallus A, Goldhaber SZ, Haas S, Huisman MV, Hull RD, Kakkar AK, Misselwitz F, Schellong S, ODIXa-DVT Study Investigators: Treatment of proximal deep-vein thrombosis with the oral direct Factor Xa inhibitor rivaroxaban (BAY 59-7939): the ODIXa-DVT (oral direct Factor Xa inhibitor BAY 59-7939 in patients with acute symptomatic deep-vein thrombosis) study. Circulation 2007, 116:180-187.

69. Schulman S, Eriksson H, Goldhaber S, Kakkar A, Kearon C, Mismetti P, Schellong SM, Baanstra D, Schnee J: Dabigatran etexilate versus warfarin in the treatment of venous thromboembolism [abstract]. Blood (ASH Annual Meeting Abstracts) 2009, 114:3. Abstract 1.

70. Schulman S, Kakkar AK, Schellong SM, Goldhaber SZ, Eriksson H, Mismetti P, Christiansen AV, Schnee J, Kearon C: A randomized trial of dabigatran versus warfarin in the treatment of acute venous thromboembolism (RE-COVER II) [abstract]. Blood (ASH Annual Meeting Abstracts) 2011, 118. Abstract 205.

71. Schulman S, Baanstra D, Eriksson H, Goldhaber SZ, Kakkar AK, Kearon C, Mismetti P, Schellong S, Schnee J, RE-SONATE Study Group: Dabigatran versus placebo for extended maintenance therapy of venous thromboembolism [abstract]. J Thromb Haemost 2011, 9(Suppl. 2):22. Abstract O-MO-037.

72. Schulman S, Eriksson H, Goldhaber SZ, Kakkar AK, Kearon C, Kvamme M, Mismetti P, Schellong S, Schnee J: Dabigatran or warfarin for extended maintenance therapy of venous thromboembolism [abstract]. J Thromb Haemost 2011, 9(Suppl. 2):731. Abstract O-TH-033.

73. Agnelli G, Buller HR, Cohen A, Curto M, Gallus AS, Johnson M, Porcari A, Raskob GE, Weitz Jl, The AMPLIFY-EXT Investigators: Apixaban for extended treatment of venous thromboembolism. N Engl J Med 2013, 368:699-708.

74. Wolf PA, Abbott RD, Kannel WB: Atrial fibrillation as an independent risk factor for stroke: the Framingham Study. Stroke 1991, 22:983-988.

75. Lin HJ, Wolf PA, Kelly-Hayes M, Beiser AS, Kase CS, Benjamin EJ, D'Agostino $\mathrm{RB}$ : Stroke severity in atrial fibrillation. The Framingham Study. Stroke 1996, 27:1760-1764.

76. Patel MR, Mahaffey KW, Garg J, Pan G, Singer DE, Hacke W, Breithardt G, Halperin JL, Hankey GJ, Piccini JP, Becker RC, Nessel CC, Paolini JF, Berkowitz SD, Fox KAA, Califf RM, ROCKET AF Investigators: Rivaroxaban versus warfarin in nonvalvular atrial fibrillation. N Engl J Med 2011, 365:883-891.

77. Tanigawa T, Kaneko M, Hashizume K, Kajikawa M, Ueda H, Tajiri M, Mueck W: Model-based dose selection for phase III rivaroxaban study in Japanese patients with non-valvular atrial fibrillation. Drug Metab Pharmacokinet 2013, 28:59-70.

78. Kaneko M, Tanigawa T, Hashizume K, Kajikawa M, Tajiri M, Paolini JF, Mueck W: Confirmation of model-based dose selection for Japanese phase III study of rivaroxaban in non-valvular atrial fibrillation patients. Drug Metab Pharmacokinet 2013. doi:10.2133/dmpk.DMPK-12-RG-109.

79. Hori M, Matsumoto M, Tanahashi N, Momomura S, Uchiyama S, Goto S, Izumi T, Koretsune Y, Kajikawa M, Kato M, Ueda H, Iwamoto K, Tajiri M: Rivaroxaban vs. warfarin in Japanese patients with atrial fibrillation - the J-ROCKET AF study. Circ J 2012, 76:2104-2111.

80. Connolly SJ, Ezekowitz MD, Yusuf S, Reilly PA, Wallentin L: Newly identified events in the RE-LY trial. N Engl J Med 2010, 363:1875-1876.

81. Connolly SJ, Ezekowitz MD, Yusuf S, Eikelboom J, Oldgren J, Parekh A, Pogue J, Reilly PA, Themeles E, Varrone J, Wang S, Alings M, Xavier D, Zhu J, Diaz R, Lewis BS, Darius H, Diener HC, Joyner CD, Wallentin L, RE-LY Steering Committee and Investigators: Dabigatran versus warfarin in patients with atrial fibrillation. N Engl J Med 2009, 361:1139-1151. 
82. Dansirikul C, Lehr T, Liesenfeld KH, Haertter S, Staab A: A combined pharmacometric analysis of dabigatran etexilate in healthy volunteers and patients with atrial fibrillation or undergoing orthopaedic surgery. Thromb Haemost 2012, 107:775-785.

83. Hariharan S, Madabushi R: Clinical pharmacology basis of deriving dosing recommendations for dabigatran in patients with severe renal impairment. J Clin Pharmacol 2012, 52:119S-125S.

84. Mega JL, Braunwald E, Wiviott SD, Bassand JP, Bhatt DL, Bode C, Burton P, Cohen M, Cook-Bruns N, Fox KA, Goto S, Murphy SA, Plotnikov AN, Schneider D, Sun X, Verheugt FW, Gibson CM: Rivaroxaban in patients with a recent acute coronary syndrome. N Engl J Med 2012, 366:9-19.

85. Mega JL, Braunwald E, Mohanavelu S, Burton P, Poulter R, Misselwitz F, Hricak V, Barnathan ES, Bordes P, Witkowski A, Markov V, Oppenheimer L, Gibson CM, ATLAS ACS-TIMI 46 study group: Rivaroxaban versus placebo in patients with acute coronary syndromes (ATLAS ACS-TIMI 46): a randomised, double-blind, phase II trial. Lancet 2009, 374:29-38.

86. Xu XS, Moore K, Burton P, Stuyckens K, Mueck W, Rossenu S, Plotnikov A, Gibson M, Vermeulen A: Population pharmacokinetics and pharmacodynamics of rivaroxaban in patients with acute coronary syndromes. Br J Clin Pharmacol 2012, 74:86-97.

87. Alexander JH, Lopes RD, James S, Kilaru R, He Y, Mohan P, Bhatt DL, Goodman S, Verheugt FW, Flather M, Huber K, Liaw D, Husted SE, LopezSendon J, De Caterina R, Jansky P, Darius H, Vinereanu D, Cornel JH, Cools F, Atar D, Leiva-Pons JL, Keltai M, Ogawa H, Pais P, Parkhomenko A, Ruzyllo W, Diaz $R$, White $H$, Ruda $M$, et al: Apixaban with antiplatelet therapy after acute coronary syndrome. N Engl J Med 2011, 365:699-708.

88. Eriksson BI, Quinlan DJ, Weitz Jl: Comparative pharmacodynamics and pharmacokinetics of oral direct thrombin and Factor Xa inhibitors in development. Clin Pharmacokinet 2009, 48:1-22.

89. Lindhoff-Last E, Samama MM, Ortel TL, Weitz Jl, Spiro TE: Assays for measuring rivaroxaban: their suitability and limitations. Ther Drug Monit 2010, 32:673-679.

90. Siegal DM, Crowther MA: Acute management of bleeding in patients on novel oral anticoagulants. Eur Heart J 2013, 34:489-498b.

91. Samama MM, Martinoli JL, Le Flem L, Guinet C, Plu-Bureau G, Depasse F, Perzborn E: Assessment of laboratory assays to measure rivaroxaban - an oral, direct Factor Xa inhibitor. Thromb Haemost 2010, 103:815-825.

92. Samama MM, Contant G, Spiro TE, Perzborn E, Flem LL, Guinet C, Gourmelin $Y$, Martinoli JL: Evaluation of the prothrombin time for measuring rivaroxaban plasma concentrations using calibrators and controls: results of a multicenter field trial. Clin Appl Thromb Hemost 2012, 18:150-158.

93. Barrett $Y C$, Wang Z, Knabb RM: A novel prothrombin time assay for assessing the anticoagulant activity of oral Factor Xa inhibitors. Clin Appl Thromb Hemost 2012. doi:10.1177/1076029612441859.

94. Douxfils J, Mullier F, Robert S, Chatelain C, Chatelain B, Dogne JM: Impact of dabigatran on a large panel of routine or specific coagulation assays. Laboratory recommendations for monitoring of dabigatran etexilate. Thromb Haemost 2012, 107:985-997.

95. Samama MM, Guinet C: Laboratory assessment of new anticoagulants. Clin Chem Lab Med 2011, 49:761-772.

96. Mani H, Rohde G, Stratmann G, Hesse C, Herth N, Schwers S, Perzborn E, Lindhoff-Last $E$ : Accurate determination of rivaroxaban levels requires different calibrator sets but not addition of antithrombin. Thromb Haemost 2012, 108:191-198.

97. Samama MM, Contant G, Spiro TE, Perzborn E, Guinet C, Gourmelin Y, Le Flem L, Rohde G, Martinoli JL: Evaluation of the anti-Factor Xa chromogenic assay for the measurement of rivaroxaban plasma concentrations using calibrators and controls. Thromb Haemost 2012, 107:379-387.

doi:10.1186/1477-9560-11-10

Cite this article as: Mueck et al: Rivaroxaban and other novel oral anticoagulants: pharmacokinetics in healthy subjects, specific patient populations and relevance of coagulation monitoring. Thrombosis Journal 2013 11:10.

\section{Submit your next manuscript to BioMed Central and take full advantage of:}

- Convenient online submission

- Thorough peer review

- No space constraints or color figure charges

- Immediate publication on acceptance

- Inclusion in PubMed, CAS, Scopus and Google Scholar

- Research which is freely available for redistribution

Submit your manuscript at www.biomedcentral.com/submit 